Article

\title{
Carbon Emission Reduction of Apparel Material Distribution Based on Multi-Objective Genetic Algorithm (NSGA-II)
}

\author{
Xujing Zhang, Lichuan Wang *(1) and Yan Chen * \\ College of Textile and Clothing Engineering, Soochow University, Suzhou 215021, China; xzhangxj@163.com \\ * Correspondence: lcwang@suda.edu.cn (L.W.); yanchen@suda.edu.cn (Y.C.)
}

Received: 3 April 2019; Accepted: 30 April 2019; Published: 4 May 2019

\begin{abstract}
Low-carbon production has become one of the top management objectives for every industry. In garment manufacturing, the material distribution process always generates high carbon emissions. In order to reduce carbon emissions and the number of operators to meet enterprises' requirements to control the cost of production and protect the environment, the paths of material distribution were analyzed to find the optimal solution. In this paper, the model of material distribution to obtain minimum carbon emissions and vehicles (operators) was established to optimize the multi-target management in three different production lines (multi-line, U-shape two-line, and U-shape three-line), while the workstations were organized in three ways: in the order of processes, in the type of machines, and in the components of garment. The NSGA-II algorithm (non-dominated sorting genetic algorithm-II) was applied to obtain the results of this model. The feasibility of the model and algorithm was verified by the practice of men's shirts manufacture. It could be found that material distribution of multi-line layout produced the least carbon emissions when the machines were arranged in the group of type.
\end{abstract}

Keywords: apparel manufacturing; carbon emission; material distribution; NSGA-II algorithm

\section{Introduction}

In recent years, the issue of greenhouse gas emissions reduction has become a popular topic in the world [1]. At the United Nations Climate Conference in Copenhagen, China promised to reduce carbon emissions per unit of GDP to $40-50 \%$ of the 2005 levels by 2020 [2]. China is the largest garment processing country with high energy consumption and high carbon emissions in the world [3,4]. Material distribution is one of the carbon sources in the garment production process. Therefore, it is an important problem for enterprises to seek a win-win situation of economic and environmental sustainability. Reduction of cost and carbon emissions are also hot issues in the research of material distribution.

The ever-increasing contradiction between the efficient production line and inefficient production logistics is the bottleneck that limits the production capacity of an enterprise [5,6]. Generally, the operators generally choose the route according to personal experience or even personal preference when distributing the materials since there are no standard routes or rules to follow, and the routes are not optimized by enterprise. As a result, the cost of production will increase, while the carbon emissions will increase due to waste of distribution cost and occupation of transportation resources [7,8]. Most importantly, choosing the route by operators' experience and preference could create some problems such as untimely distribution of material, lacking materials in some workstations, even stopping production, and increasing production costs $[9,10]$. Before sewing, the garment materials-including clothing pieces and accessories-need to be distributed to the relevant workstations. Garment sewing 
involves many processes [11]. Apparel companies hope that materials can be distributed in a timely manner and reduce distribution costs, thereby improving production efficiency, and increasing corporate profits. Just-in-time distribution aims to accurately deliver materials to the required workstations at the right time and in the right way [12]. Therefore, the material distribution route and personnel should be reasonably planned to achieve on-time distribution for the purpose of high efficiency of material distribution.

The production lines should be arranged according to market and orders since apparel is a fast fashion industry [13]. Generally, the production mode of garments is divided into three different types: mass production, medium batch production [14], and multi-variety small batch production [15]. Due to the different workstation arrangements in different production modes, the materials required for each workstation are different. It is necessary to arrange the material distribution path reasonably for different production modes.

Generally, the distribution of materials before sewing is carried out by the operators using carts, so the breathing carbon emissions generated by the operators are mainly considered in this paper. Material distribution is a complex problem involving multiple constraints because there are many factors involved in this process. For example, it is necessary to consider that the material should be distributed accurately and efficiently since the cost of production could be reduced by minimizing the consumption of distribution, while the environment could be protected by minimizing carbon emissions. It is necessary to establish a comprehensive optimization model including the factors of operator number and carbon emissions.

In this paper, application analysis of the material distribution model was carried out using the sewing production of men's shirts. It is expected to reflect the actual situation of carbon emissions in materials distribution. The NSGA-II algorithm was applied to obtain the results of carbon emissions in different production lines. The optimal path of material distribution in different workstation layouts can be found according to the results obtained from the model calculation. Thus, this paper is organized as follows: a literature review of related work is presented in Section 2. The assumptions, constraints, and objective functions of the material distribution model are described in Section 3. The NSGA-II algorithm design is specifically described in Section 4. Taking men's shirts as an example, the material distribution of different workstation layouts and different production line layouts are optimized. Each optimization scheme was compared to one another to select an effective solution. Detailed experimental design and results are presented in Section 5. Discussion is illustrated in Section 6. In Section 7, several conclusions were summarized.

\section{Literature Review}

The main idea of this paper is to obtain an optimal distribution plan with consideration of carbon emissions and the number of operators in garment material distribution. We review the literature about the material distribution problem in two areas: research about material distribution optimization, and research about carbon emissions.

\subsection{Research Concerning Material Distribution Optimization}

In order to optimize the material distribution paths for reducing cost of production, and improving market competitiveness of enterprises, some researchers have established different multi-objective model of material distribution path based on the different objectives and impact factors [16]. For example, Mohammad Rahimi [17] posed a new idea about inventory path, based on the level of service in the distribution of perishable products-considered by determining the specific expiration date, and established a multi-objective mathematical model to maximize profit, minimize delay rate, and minimize the number of vehicles. Keivan Ghoseiri [18] established a multi-objective path optimization model, which can minimize the total cost of transportation and transit time. Cheikh Mohamed [19] used a hybrid genetic algorithm to solve the multi-objective path optimization model—with a minimal cost of transportation and total travel time. 
NSGA II is an improved version of NSGA (non-dominated sorting genetic algorithm) and was originally proposed by Deb et al. [20,21]. A few variants of the NSGA II algorithm have been used for solving multi objective vehicle routing problems, e.g. for solving vehicle routing problem with route balancing [22], for solving multi objective vehicle routing problems with time windows [23] and for solving a green vehicle routing problems [24]. Multi objective genetic algorithms for the solution of multi objective vehicle routing problems have been used in $[25,26]$.

From the research on material distribution above, we see that these studies are aimed at achieving the lowest cost, without accounting for environmental factors and attention to a delivery time window.

\subsection{Research Concerning Carbon Emissions}

More and more people are realizing the importance of the low-carbon economy with the steadily increasing awareness of environmental protection. Low-carbon manufacturing has become a hot topic as a result of the service advantage and cost advantage. Therefore, under the premise of ensuring service and cost advantages, the model of material distribution for low carbon emissions would be a useful and efficient tool to enhance the international competitiveness of enterprises.

In the past few years, the issue of green material distribution has received more attention. $\mathrm{Wu}$ W. [27] proposed a multi-objective optimization problem of water distribution systems that accounts for two objectives: the minimization of total cost and the minimization of GHG emissions. Soysal et al. [28] proposed a model of food logistic network with carbon emissions consideration for an international beef supply chain. Bauer et al. [29] proposed an application to minimize greenhouse gas emissions for railway service. A hybrid ant colony system, green capacitated vehicle routing problem in sustainable transportation was proposed by Adiba et al. [30] and they developed a technique to estimate the quantity of the carbon dioxide emissions and emissions matrix, which were integrated into the CVRP model. Erdoğan and Miller-Hooks [31] developed and conceptualized a green vehicle routing problem. A vehicle routing problem, simultaneous pick-up and distribution, was proposed by Montané and Galvão [32]. Figliozzi [33] proposed a vehicle routing problem for emissions minimization. Kuo et al. [34] developed a carbon footprint inventory path for hot spot suppliers' planning and selection. Konur [35] developed carbon constrained integrated inventory control and truckload transportation with heterogeneous freight trucks.

Through the abovementioned literature, it can be found that in solving the green and material distribution problems, existing contributions focus on how to transform multi-objective optimization into single-objective optimization [36,37], ignoring the balance of multi-objectives. In addition, these consider the delivery time window [38] without using it as a constraint. Most research related to the optimization of material distribution focuses on urban freight transportation and assembly production lines, such as automobile assembly line [39-41].

In summary, there is still little research on material distribution of garment production lines that considers the two factors of the economy and environment at the same time. Thus, this paper proposes a comprehensive model for garment material distribution considering carbon emissions and the number of operators to optimize distribution paths. This study can provide guidance for enterprises to achieve green and sustainable development.

\section{Model Formulation}

The problem of the material distribution path is usually optimized with a single goal such as minimizing transportation cost or minimizing distribution distance [17-19]. However, manufacturers hope to achieve multiple objectives of carbon emissions reduction while saving cost, so it is necessary to establish a multi-objective optimization model. The assumptions of the model are described in Section 3.1, constraints of the model are introduced in Section 3.2. The objective functions of the model are presented in Section 3.3. 


\subsection{Assumptions}

In order to maintain the reasonable and scientific nature of the hypothesis, the mathematical models in this paper are supported by literature references [42-44]. The assumptions for the establishment of the multi-objective model are listed as follows:

1. There is only one distribution center.

2. The locations of material distribution center and each workstation are known.

3. The material requirements for each workstation are known.

4. The requirements of each workstation must be met.

5. The type and the loading capacity of vehicles are known.

6. Vehicles must not be overloaded during material distribution.

\subsection{Constraints}

According to assumptions and the needs to build the model, constraints are proposed. The notations are used in this research that focus on a deterministic model denote as material distribution are defined in Table 1.

Table 1. Notation list.

\begin{tabular}{|c|c|}
\hline Item & Illustration \\
\hline$N$ & Total number of material demand workstations \\
\hline M & $\begin{array}{l}\text { Total number of vehicles for material distribution (Because the operator uses the } \\
\text { cart for delivery, the total number of operators responsible for material } \\
\text { distribution tasks is also M.) }\end{array}$ \\
\hline Z & Total carbon emissions of material distribution, $\mathrm{kgCO}_{2} e$ \\
\hline$D$ & Total number of material distribution vehicles \\
\hline$i$ & Index of material demand workstation, where $i=1,2, \ldots, N$ \\
\hline$j$ & Index of material demand workstation other than workstation $i$, where $j=1,2 \cdot N$ \\
\hline$g_{i}$ & Material quantity demand of workstation $i$, pieces \\
\hline$\left[a_{i}, b_{i}\right]$ & Time window for material distribution of workstation $i, \mathrm{~s}$ \\
\hline$t_{i}$ & Time point when the vehicle arrives or leaves workstation $i, \mathrm{t}_{\mathrm{i}} \in\left(\mathrm{a}_{\mathrm{i}}, \mathrm{b}_{\mathrm{i}}\right)$. \\
\hline$x_{i j m}$ & $\begin{array}{l}\text { 1: if vehicle (operator) } \mathrm{m} \text { passes the route between workstation } i \text { and workstation } \\
\qquad j ; 0: \text { otherwise }\end{array}$ \\
\hline$y_{i m}$ & $\begin{array}{l}\text { 1: if vehicle(operator) } \mathrm{m} \text { is responsible for workstation } i \text {; } 0 \text { : otherwise } \\
\text { Carbon emission coefficient of the operator's breathing } \mathrm{kgCO} e / s\end{array}$ \\
\hline $\begin{array}{c}K \\
H_{m}\end{array}$ & Short-term respiratory minute volume () of Chinese residents, $\mathrm{L} / \mathrm{min}$ \\
\hline$V$ & $\begin{array}{l}\text { Vehicles speed of material distribution (walking speed of the operators for } \\
\text { material distribution), } \mathrm{m} / \mathrm{s}\end{array}$ \\
\hline$L$ & Distance between workstations the material distributed, $m$ \\
\hline 0 & Distribution center \\
\hline
\end{tabular}

Constraint formulation is shown in Equations (1)-(5). Equation (1) ensures only one vehicle (operator) for a workstation. Each workstation can be assigned to an operator. Every operator has a material vehicle of the same capacity and distributes material to workstations. Equation (2) sets the constraint that the material demand on each path cannot exceed the load capacity of the vehicle. Equation (3) ensures that the distribution vehicle starts from the distribution center. Equation (4) sets the constraint of the time requirements for each workstation. Equation (5) ensures that distribution vehicles (operators) return to the distribution center after completion of distribution.

$$
\sum_{m=1}^{M} y_{i m}=1
$$




$$
\begin{gathered}
\sum_{i=1}^{N} g_{i} y_{i m} \leq Q \\
\sum_{m=1}^{M} y_{0 m}=M \\
a_{i} \leq t_{i} \leq b_{i} \\
\sum_{m=1}^{M} \sum_{i=1}^{N} x_{i 0 m}=M
\end{gathered}
$$

\subsection{Objective Functions}

The multi-objective optimization model of garment material distribution considering carbon emission is proposed to realize the path selection of low-carbon distribution. Carbon emissions in the process of garment material distribution mainly come from the respiration of operators since the vehicles do not consume energy, while the carbon emissions from the breathing of operators distributing materials are associated with the distance and speed of walking intensity. If we only put the minimum carbon emissions as the optimization goal, it is pointless for enterprises. Therefore, the objective function is not to minimize carbon emissions, but to use the minimum number of vehicles (operators) as objective function when we establish the mathematical model.

Objective 1: Minimum carbon emissions.

$$
Z_{\text {min }}=\sum_{i=0}^{N} \sum_{j=0}^{N} \sum_{m=1}^{M} L_{i j} x_{i j m} \frac{K}{V}
$$

Objective 2: Minimum number of vehicles (operators).

$$
D_{\min }=\sum_{i=0}^{N} \sum_{m=1}^{M} x_{0 i m}
$$

\section{Methodology}

To optimize the model of material distribution to obtain minimum carbon emissions and vehicles (operators), a multi objective method is required. A multi objective method can be applied by using many different algorithms. Among these algorithms, genetic algorithms have been shown to be effective in solving material distribution optimization problems in many researches [45-47]. In this study, the NSGA-II algorithm is applied to calculate the multi-objective optimization model of material distribution. The optimization procedure using NSGA-II is summarized in Figure 1, and the steps of genetic algorithm as follows. 


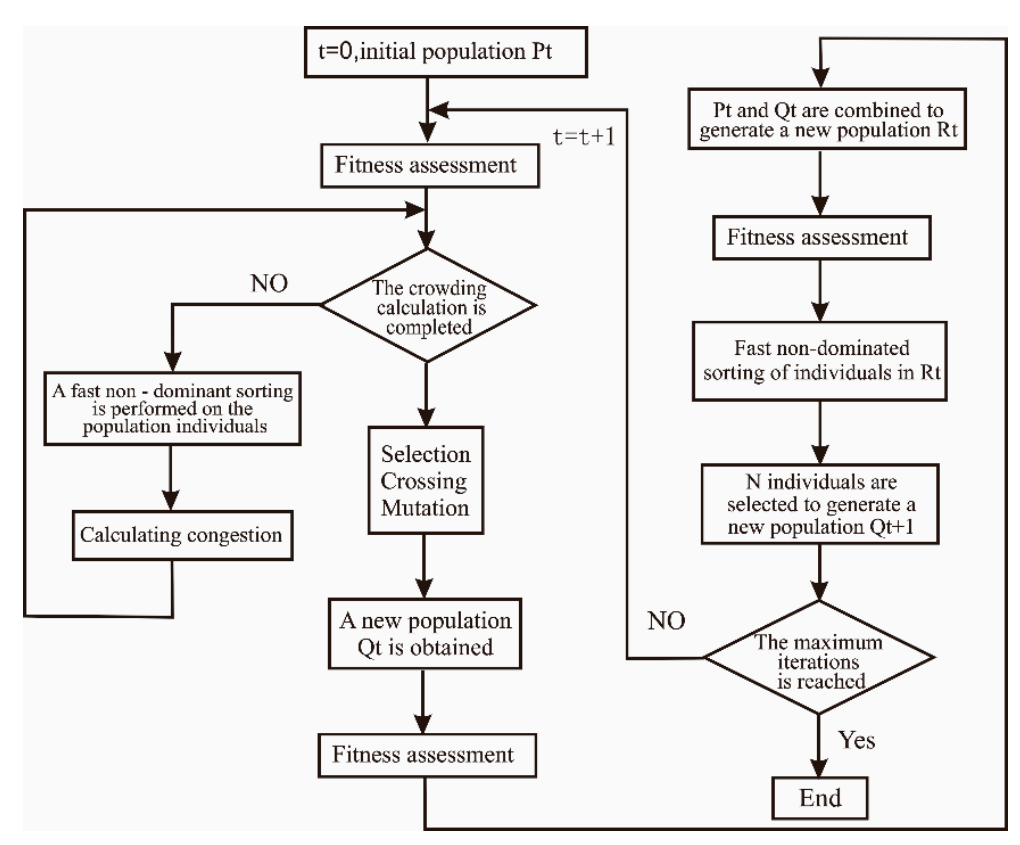

Figure 1. NSGA-II algorithm flow chart.

Step 1: Workstations are coded by real numbers (Section 4.1).

Step 2: The population size is set, and the initial population (Section 4.2) is generated according to the constraints.

Step 3: According to the objective function value of each individual, the fast non-dominated sorting (Section 3.3) and the virtual crowding distance (Section 4.3) of the contemporary population are calculated.

Step 4: According to the calculation results of sorting and crowding distance, two individuals are randomly selected for crossover (Section 4.5) and mutation (Section 4.5) by using the tournament mechanism (Section 4.4).

Step 5: The elite retention strategy is carried out (Section 4.4). The parent population and the child population are combined. The combined population is selected by fast non-dominated sorting and virtual crowding distance, and then a new generation population is generated.

Step 6: The number of iterations is increased by 1, returning to Step 3. This loop continues until the maximum number of iterations is reached.

\subsection{Coding}

The chromosomes are coded in real numbers. Since the number of vehicles (operators) is uncertain, the code does not add the distribution center (0) as a path separator to the chromosome structure according to the general distribution vehicle path optimization models. However, all the workstations are coded directly into one chromosome. This chromosomal coding method ensures that the distribution of each workstation is not duplication.

For example, three distribution vehicles (operators) are used to distribute material for nine workstations, assuming there is a solution (347125689) and (123), the permutation is the permutation as shown in Figure 2. 


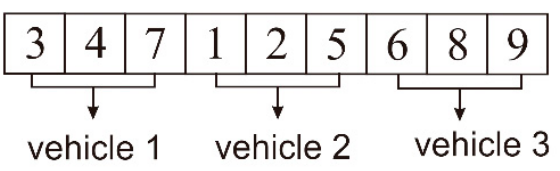

vehicle 1 vehicle 2 vehicle 3

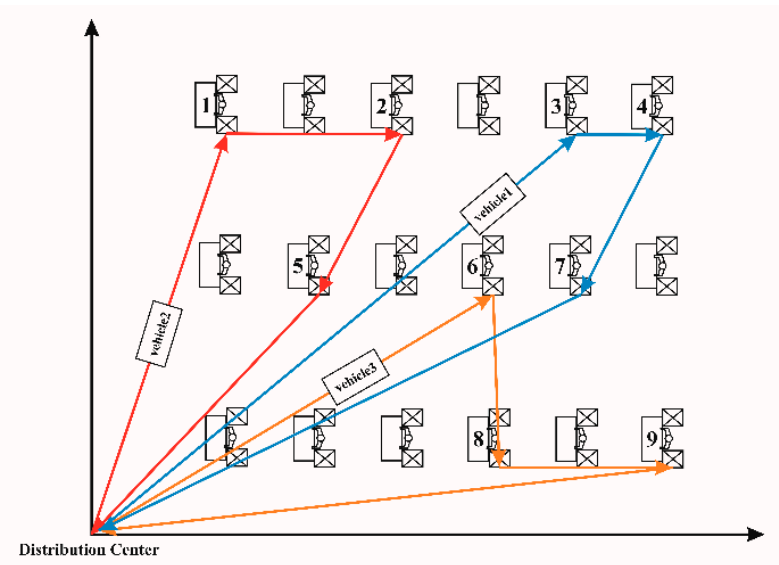

(b)

Figure 2. Example of coding operation (unnumbered workstations are not delivered): (a) Path encoding expression; (b) Material distribution path.

In this example, the vehicle 1 (operator 1) provides distribution service for workstations 3,4 , and 7 ; workstations 1,2 , and 5 are distributed by vehicle 2 (operator2); and vehicle 3 (operator 3 ) provides distribution service for workstations 6,8 , and 9 . The corresponding distribution paths can be described:

Sub-path 1: 0-3-4-7-0

Sub-path 2: 0-1-2-5-0

Sub-path 3: 0-6-8-9-0

\subsection{Decoding and Population Initialization}

The decoding method can be illustrated as following steps:

Step 1: A new distribution path is initialized.

Step 2: The gene elements in the chromosome are sequentially inserted into the current distribution path. If the insertion of the gene value causes the loading of the distribution path to exceed the maximum capacity of the vehicle or return to the distribution center later than the latest return time or the arrival time is earlier than the earliest arrival time, then a new distribution path is constructed.

Step 3: The above operations are repeated until all the workstations that needed to be distributed are inserted into the distribution path.

The initial population is generated in a random manner. Since each individual is a full array of 1 to $n$, the initial population randomly generates chromosomes that satisfy the population size.

\subsection{Fast Non-Dominated Sorting and Calculating Congestion}

The fast non-dominated sorting solution is found and classified into a first-level non-dominated solution. After that, a new non-dominated solution is found in the remaining solutions and classified into a second-level non-dominated solution. The loop will run in turn until all solutions are assigned.

When the ranks of the non-dominated solutions are the same to each other, it is necessary to distinguish the advantages and disadvantages, according to the crowding distance of the non-dominated solutions. The evenly distributed solution is preferentially selected since the relatively large crowding distance.

\subsection{Operation Selection}

The selected population evolution is close to the position of the non-dominated optimal solution for the purpose of the average dispersion of the non-dominated solution frontier. The method of 
binary tournament selection is to arbitrarily select two non-dominated solutions ( $i$ and $j$ ) and put them into the mating pool. The individual $i$ is better than $j$ when the non-dominated level $\operatorname{rank}_{i}<\operatorname{rank}_{j}$; if $\operatorname{rank}_{i}=\operatorname{rank}_{j}$, the congestion distance is $d(i)_{\text {distance }}>d(j)_{\text {distance }}$. Elite retention strategies are adopted to accelerate the rate of convergence.

\subsection{Crossing Operation and Mutation Operation}

The crossover method is involved in two points of intersection. Two intersections are randomly set in the individual code string, and then the partial gene exchange is performed. It is assumed that the two parent chromosomes are "parent $1=347125689$ ", "parent $2=215843769$ ", and a crossover region is randomly selected in the parent chromosome, where the red dotted line is the crossover region. The intersections in the two chromosomes are interchanged to obtain two new chromosomes (proto-child1 and proto-child 2). The schematic diagram of the crossover process is shown in Figure 3.

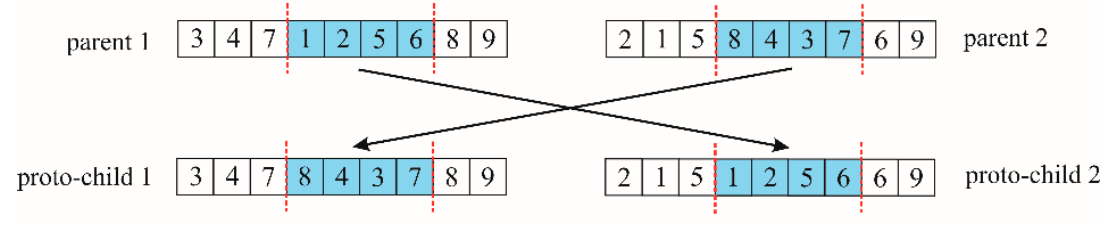

Figure 3. Example of crossing operation.

A flip mutation method is adopted to increase the diversity of chromosomes after mutation. The variant parent is obtained based on the probability of mutation. The two mutation points of the parent chromosome are selected at random, while the child variant individuals are obtained by the flipping operation. The chromosome is assumed as "217385946", and two mutation points are randomly selected on the chromosome, where the red dotted line is the mutation region. The genes in the mutation region are inserted into the original gene position in reverse order to obtain a new chromosome. The schematic diagram of the mutation process is shown in the Figure 4.

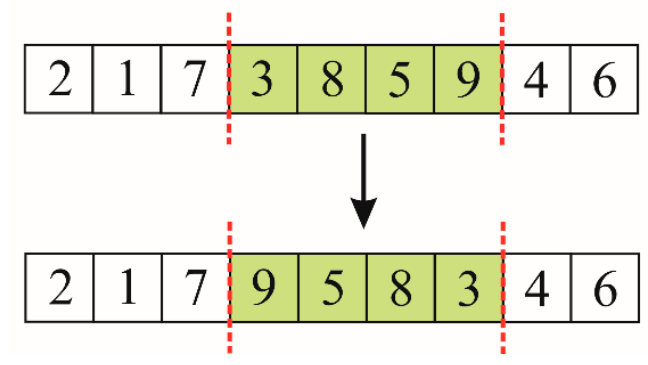

Figure 4. Example of inversion mutation operation.

\section{Case Study}

The material distribution schemes of the three production line layouts (multi-line, U-shape two-line, U-shape three-line) of the men's shirts in the three workstation layouts: process workstation layout, machine workstation layout, and garment components workstation layout (PWL, MWL, and GWL) were optimized by the model, and the carbon emissions and the number of operators for the material distribution of each scheme were calculated. The number of operators and carbon emissions of the material distribution of the three production line layouts under each workstation layout were compared and analyzed, and the production line layout with the lowest carbon emission and minimum number of operators for each workstation layout was obtained. Enterprises could reduce the cost of transportation and carbon emissions under certain conditions, while the material could be sent to each workstation in an accurate and timely manner. Sections 5.1 and 5.2 describe examples of experiment problems in this paper and the design of the parameters of the model and algorithm. The experimental results are analyzed in Section 5.3. 


\subsection{Arrangement of Production Line}

Generally, the production line can be arranged by three different layouts. In the order of process workstation layout (PWL) is to arrange the workstations according to the processing order of the men's shirt. In the type of machine workstation layout (MWL) is that machines required for the same processing contents are arranged in one workstation. The components of the garment components workstation layout (GWL) is to produce each garment component as a workstation. In this paper, the production lines were laid out according to multiple-line (Figure 5a), U-shape two-line (Figure 5b), and U-shape three-line (Figure 5c), as shown in Figure 5.

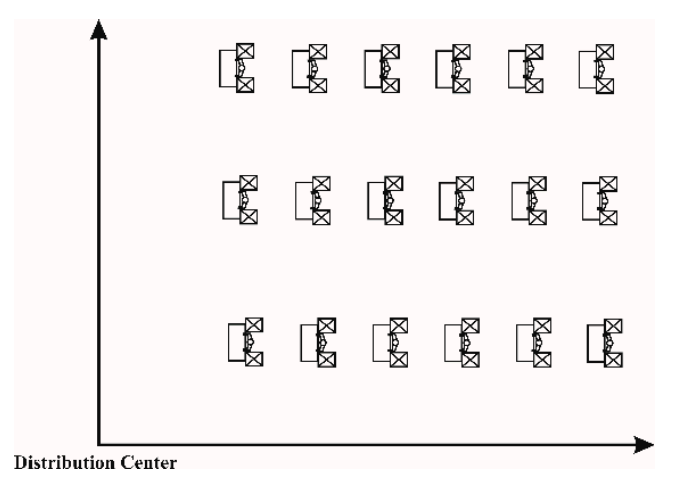

(a)

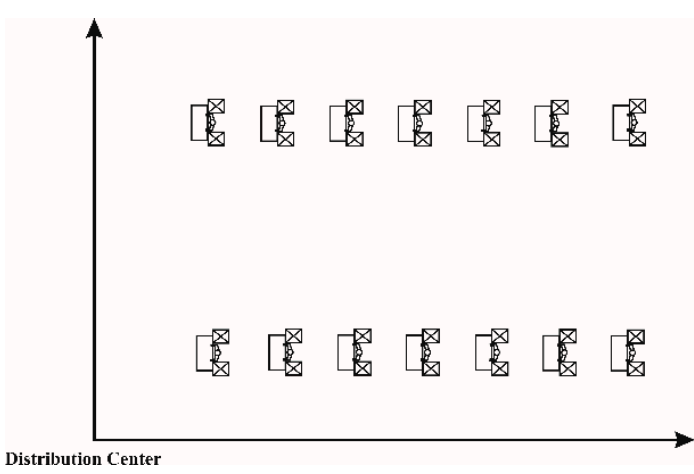

(b)

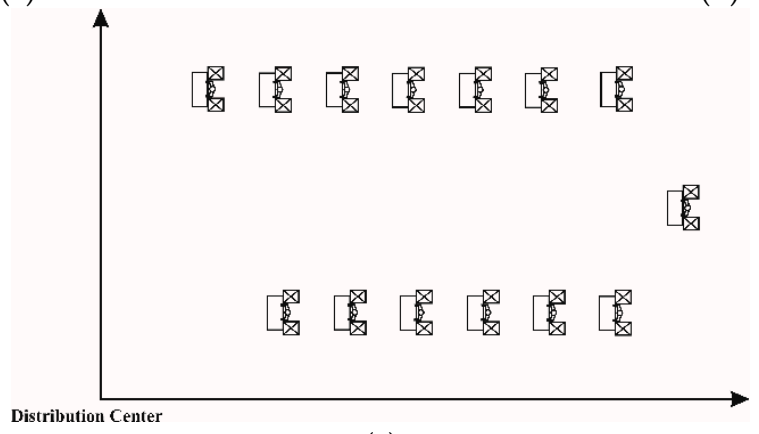

(c)

Figure 5. Diagrams of different production line layouts: (a) multiple-line layout; (b) U-shape two-line layout; (c) U-shape three-line layout.

\subsection{Experiment Data and Parameter Setting}

The position coordinates of workstations, the quantity of material distributed at each workstation, the earliest time allowed for vehicle arrived at the workstations, the latest time allowed for vehicles leaving the workstations, and operators' service time for placing materials on the workstations in three production line layouts (multi-line, U-shape two-line, U-shape three-line) of men's shirts based on different workstations layouts (PWL, MWL, and GWL) were shown in Table 2.

The production cycle of each workstation was not much different since the production line was optimized by balance, so the material was distributed in batches. The daily output of men's shirts was 600 pieces, while the material was bundled in 20 pieces. Each workstation required 2 bundles of material and to be distributed 15 times. The capacity of the vehicle was 20 bundles.

According to the literature [48], short-term respiratory minute volume of Chinese residents was summarized, as shown in Table 3. The respiratory minute volume of residents in China was different under different activities. According to the references [48,49], 0.03\% of air inhaled by human body was $\mathrm{CO}_{2}$, while $4.4 \%$ of the exhaled air was $\mathrm{CO}_{2}$, generally, the density of $\mathrm{CO}_{2}$ was $1.98 \mathrm{~g} / \mathrm{L}$. Thus, the carbon emission factor of human breathing was calculated by Equation (8)

$$
K=1.98 \times 4.4 \% \times H_{m}
$$


Table 2. Data sheet of workstations based on PWL, MWL, and GWL.

\begin{tabular}{|c|c|c|c|c|c|c|c|c|}
\hline \multirow{2}{*}{$\begin{array}{l}\text { Workstation } \\
\text { Layout }\end{array}$} & \multirow{2}{*}{$\begin{array}{l}\text { Workstation } \\
\text { Number }\end{array}$} & \multicolumn{3}{|c|}{ Coordinate } & \multirow{2}{*}{ Quantity/Bundle } & \multirow{2}{*}{$\begin{array}{c}\text { Earliest } \\
\text { Time/s }\end{array}$} & \multirow{2}{*}{$\begin{array}{l}\text { Latest } \\
\text { Time/s }\end{array}$} & \multirow{2}{*}{$\begin{array}{l}\text { Service } \\
\text { Time/s }\end{array}$} \\
\hline & & Multi-Line & $\begin{array}{l}\text { U-Shape } \\
\text { Two-Line }\end{array}$ & $\begin{array}{l}\text { U-Shape } \\
\text { Three-Line }\end{array}$ & & & & \\
\hline \multirow{8}{*}{ PWL } & 1 & 18,8 & 16,3 & 16,3 & 6 & 0 & 40 & 20 \\
\hline & 2 & 7,18 & 16,8 & 21,11 & 10 & 0 & 40 & 20 \\
\hline & 3 & 14,3 & 9,3 & 24,3 & 8 & 0 & 84 & 20 \\
\hline & 4 & 15,8 & 25,3 & 13,3 & 8 & 0 & 40 & 20 \\
\hline & 5 & 13,12 & 10,8 & 11,11 & 2 & 0 & 50 & 10 \\
\hline & 6 & 7,8 & 36,3 & 33,6 & 8 & 20 & 80 & 20 \\
\hline & 7 & 19,12 & 39,8 & 28,3 & 2 & 5 & 65 & 10 \\
\hline & 8 & 9,3 & 18,3 & 19,3 & 6 & 20 & 60 & 20 \\
\hline \multirow{9}{*}{ MWL } & 1 & 18,12 & 6,3 & 30,4 & 4 & 20 & 80 & 20 \\
\hline & 2 & 10,8 & 3,3 & 6,4 & 2 & 20 & 94 & 10 \\
\hline & 3 & 19,8 & 13,3 & 32,4 & 6 & 0 & 50 & 10 \\
\hline & 4 & 8,4 & 23,3 & 9,13 & 4 & 20 & 60 & 20 \\
\hline & 5 & 13,8 & 21,3 & 18,13 & 2 & 5 & 65 & 10 \\
\hline & 6 & 16,8 & 17,3 & 33,8 & 12 & 0 & 40 & 20 \\
\hline & 7 & 18,4 & 25,8 & 22,4 & 8 & 0 & 40 & 20 \\
\hline & 8 & 12,4 & 37,8 & 14,4 & 4 & 0 & 60 & 20 \\
\hline & 9 & 9,18 & 31,8 & 23,13 & 8 & 0 & 40 & 20 \\
\hline \multirow{10}{*}{ GWL } & 1 & 24,4 & 51,10 & 39,4 & 4 & 0 & 40 & 20 \\
\hline & 2 & 22,11 & 26,4 & 28,4 & 2 & 0 & 50 & 10 \\
\hline & 3 & 22,17 & 36,10 & 33,4 & 12 & 0 & 40 & 20 \\
\hline & 4 & 13,4 & 22,4 & 18,14 & 10 & 0 & 40 & 20 \\
\hline & 5 & 19,4 & 20,4 & 21,4 & 4 & 0 & 40 & 20 \\
\hline & 6 & 8,22 & 6,9 & 34,9 & 2 & 78 & 138 & 10 \\
\hline & 7 & 11,17 & 6,10 & 40,14 & 10 & 0 & 60 & 20 \\
\hline & 8 & 6,11 & 12. 2 & 46,14 & 2 & 5 & 65 & 10 \\
\hline & 9 & 26,11 & 30,4 & 35,14 & 2 & 225 & 285 & 10 \\
\hline & 10 & 18,22 & 47,10 & 11,4 & 2 & 20 & 80 & 10 \\
\hline
\end{tabular}

Table 3. Short-term respiratory minute volume of Chinese residents.

\begin{tabular}{ccccccc}
\hline $\begin{array}{c}\text { Activity } \\
\text { Level }\end{array}$ & Rest & Sit & $\begin{array}{c}\text { Minor } \\
\text { Activity }\end{array}$ & $\begin{array}{c}\text { Moderate } \\
\text { Activity }\end{array}$ & $\begin{array}{c}\text { Heavy } \\
\text { Physical } \\
\text { Activity }\end{array}$ & $\begin{array}{c}\text { Extreme } \\
\text { Physical } \\
\text { Activity }\end{array}$ \\
\hline $\begin{array}{c}\text { Respiratory } \\
\text { volume/L/min }\end{array}$ & 6.1 & 7.3 & 9.1 & 24.4 & 36.6 & 60.9 \\
\hline
\end{tabular}

Garment material distribution was considered heavy physical labor here. The respiratory minute volume of the distribution operator was $36.6 \mathrm{~L} / \mathrm{min}$. Thus, the carbon emission coefficient of the distribution operators' breathing was $\mathrm{K}=0.53 \times 10^{-4} \mathrm{kgCO}_{2} \mathrm{e} / \mathrm{s}$. The walking speed of the materials delivered by the operator was $1 \mathrm{~m} / \mathrm{s}$. The initial population size of the NSGA-II algorithm was 200, and its genetic algebra was 500 . The algorithm is run 20 times repeatedly.

\subsection{Analysis of Results}

After the model was calculated by NSGA-II algorithm, the material distribution schemes and distances of multi-line, U-shape two-line, U-shape three-line according to PWL, MWL, and GWL were shown in Table 4.

As shown in Table 4, there were eight workstations to distribute material to in the production line arranged by PWL, nine workstations to distribute material to in the production line arranged by MWL. Both of them required four operators (vehicles) to distribute material in a timely and accurate manner. According to the production line arranged by GWL, there were five operators (vehicles) to distribute material for 10 workstations. 
Table 4. Material distribution path based on the PWL, MWL, and GWL.

\begin{tabular}{|c|c|c|c|c|c|c|c|c|c|}
\hline \multirow{2}{*}{$\begin{array}{c}\text { Workstation } \\
\text { Layout }\end{array}$} & \multirow{2}{*}{$\begin{array}{l}\text { Vehicle } \\
\text { Number }\end{array}$} & \multicolumn{2}{|c|}{ Multi-Line } & \multicolumn{3}{|c|}{ U-Shape Two-Line } & \multicolumn{3}{|c|}{ U-Shape Three-Line } \\
\hline & & $\begin{array}{c}\text { Path } \\
\text { Scheme }\end{array}$ & Distance /m & $\begin{array}{l}\text { Vehicle } \\
\text { Number }\end{array}$ & $\begin{array}{c}\text { Path } \\
\text { Scheme }\end{array}$ & Distance /m & $\begin{array}{l}\text { Vehicle } \\
\text { Number }\end{array}$ & $\begin{array}{c}\text { Path } \\
\text { Scheme }\end{array}$ & Distance /m \\
\hline \multirow{3}{*}{ PWL } & 2 & $0-1-7-0$ & 936 & 2 & $0-1-0$ & 563 & 2 & $0-8-7-6-0$ & 1194 \\
\hline & 3 & $0-4-5-0$ & 813 & 3 & $0-4-8-0$ & 820 & 3 & $0-2-3-0$ & 1052 \\
\hline & 4 & $0-2-6-0$ & 739 & 4 & $0-5-7-6-0$ & 1392 & 4 & $0-1-0$ & 558 \\
\hline \multirow{3}{*}{ MWL } & 2 & $0-8-4-0$ & 475 & 2 & $0-8-2-0$ & 1338 & 2 & $0-4-1-0$ & 1265 \\
\hline & 3 & $0-7-3-1-0$ & 939 & 3 & $0-3-6-5$ & 351 & 3 & $0-9-5-2-0$ & 1071 \\
\hline & 4 & $0-9-2-0$ & 838 & 4 & $0-7-4-0$ & 980 & 4 & $0-3-6-0$ & 1230 \\
\hline \multirow{2}{*}{ GWL } & 1 & $0-4-7-0$ & 887 & 1 & $0-5-6-0$ & 896 & 1 & $0-5-10-0$ & 748 \\
\hline & 2 & $0-5-0$ & 682 & 2 & $0-3-10-0$ & 1694 & 2 & $0-4-0$ & 475 \\
\hline
\end{tabular}

The multi-line layout of the three workstation layouts had the shortest distribution distance, and the U-shape three-line layout has the longest distribution distance. Among them, the distribution distances of the multi-line and U-shape two-line layouts for MWL were the shortest. The U-shape three-line distribution distance of PWL was the shortest.

The carbon emissions of different production line layouts were calculated and shown in Figure 6. It was easy to find that the quantity of carbon emissions in multi-line $\left(0.159 \mathrm{kgCO}_{2} \mathrm{e} /\right.$ day $)$ arranged by PWL was close to the quantity of carbon emissions in multi-line arranged by MWL $\left(0.158 \mathrm{kgCO}_{2} \mathrm{e} /\right.$ day), which was the lowest quantity of carbon emission among nine production lines. In the opposite, the total carbon emissions $\left(0.324 \mathrm{kgCO}_{2} \mathrm{e} /\right.$ day $)$ in U-shape three-line arranged by GWL was higher than others. In further, it is obvious to find that the U-shape two-line $\left(0.185 \mathrm{kgCO}_{2} \mathrm{e} / \mathrm{day}\right)$ and U-shape three-line $\left(0.187 \mathrm{kgCO}_{2} \mathrm{e} /\right.$ day) have similar but different quantities of carbon emissions when they are arranged by PWL, while the lowest and highest quantities of carbon emissions in the three types production line were multi-line and U-shape three-line even with production arranged by different workstation layouts.

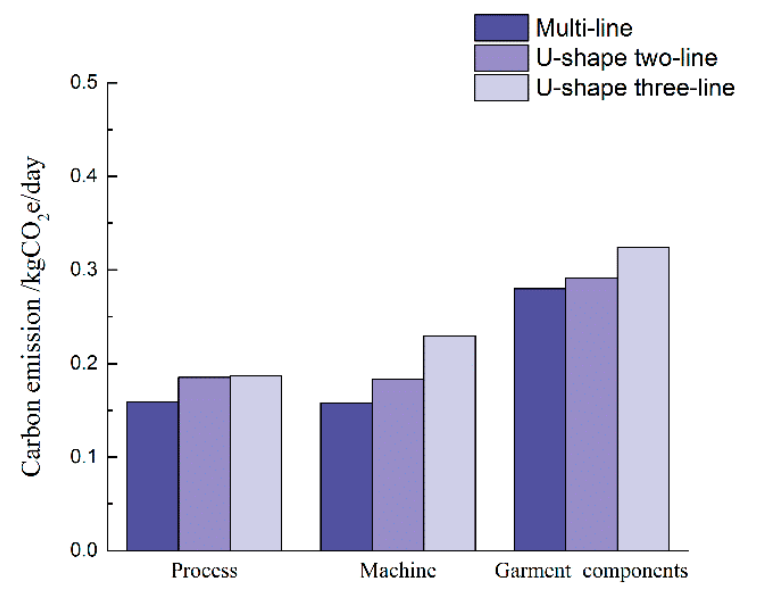

Figure 6. Carbon emissions of men's shirt material distribution.

\section{Discussion}

The material distribution of garment production mainly depends on manpower, and the carbon emissions come from operators' breathing. Therefore, the distance of distribution is crucial, which is consistent with the conclusion of material distribution in other manufacturing industries [42-44]. 
In many studies, the material distribution problem mainly considers the vehicle load, ignoring the uncertainty of the number of vehicles (operators) $[17,18]$. The model also considers the number of vehicles (operators), and the experiment results are closer to reality than the general material distribution problem.

In the modern garment production system, for the mass production mode, the process flow workstation layout is often adopted [50]. For the medium batch production mode, the machine type workstation layout is often used. For multi-variety small-batch production mode, the workstation layout of garment components is often used [51,52]. In this study, low-carbon distribution schemes for different production line layouts according to different workstation layouts are obtained.

The different types of production lines have different numbers of workstations, while position coordinates of workstations, the quantity of materials distributed at each workstation, the earliest time of vehicle arrival, the latest time of vehicle departure, and the service time are different from each other. As shown in the Figure 5, the shape of multiple-line layout is similar to the U-shape two-line layout's shape but very different to the shape of the U-shape two-line layout, it can be easy to conclude that the multi-line layout and U-shape two-line layout can arrange more machines in the certain space, while the U-shape three-line layout needs more space to arrange the same number of machines. Above all, the layouts of multi-line and U-shape two-line can be better production line types for companies with restricted area or companies that want to arrange more machines in their factories.

As better types of production lines are adopted, it is important to arrange the workstations by an effective methodology rather than arranging them randomly. Generally, the machines can be arranged by three different workstation layouts (PWL, MWL, and GWL) s. Different from the random arrangement of the workstations, the three workstation layouts (PWL, MWL, and GWL) are more reasonable since not only can they save the distribution distance but also can decrease the cost of the production. Among the three workstation layouts, the PWL needs fewer (8) workstations, while the GWL needs more (10) workstations. Three different workstation layouts all have the same minimum quantity of distribution materials (2 bundles), but different maximum quantities of distribution materials. Although, the PWL and MWL have the same earliest time (20 s) of vehicle arrival, but the GWL has the extremely high earliest time ( $225 \mathrm{~s}$ ) of vehicle arrived. The latest time of vehicle left from PWL, MWL, and GWL are $84 \mathrm{~s}, 94 \mathrm{~s}$, and $285 \mathrm{~s}$. However, all of them have the same maximum $(20 \mathrm{~s})$ and minimum (10 s) service time.

Above all, the multi-line production line arranged by MWL could be a good way to arrange the workstations in the factory to save area and reduce distribution distance. The optimized production lines shown that the multi-line production line arranged by MWL has the lowest carbon emission, while the U-shape three-line production line arranged by GWL has the maximum carbon emission.

\section{Conclusions}

Material distribution is a crucial link in reducing the production costs of garment manufacturing. Material distribution problems have been studied and solved in many previous works. However, few studies have considered path optimization based on carbon emissions. This paper aims to deal with carbon emission optimization of material distribution with time windows for garment production. A multi-objective optimization model with minimum carbon emissions and the minimum number of distribution operators is established. The NSGA-II algorithm with fast non-dominated solution ordering and elite strategy is used to solve the problem, so that the optimal solution can be obtained faster. Production lines with different layouts of men's shirts are taken as examples for verification. In the optimized material distribution scheme, among the material distributions of three production line layouts, PWL produced the lowest carbon emissions. The material distributions of multi-line production line layout for three workstation layouts produces the lowest carbon emissions.

In order to adapt to market development, garment production also needs to meet the production requirements of different products. In this paper, the material distribution schemes of low carbon emissions in different production line layouts are analyzed by an example. The experimental results of 
this paper provide a variety of material distribution solutions for apparel manufacturers. Apparel manufacturers can select the corresponding material distribution scheme according to their actual production conditions. The research design and method of this model can also be applied to other industries, such as automobile material distribution problems of an assembly workshop. With the development of the market, production lines can produce different types and quantities of products with order requirements, resulting in more types and quantities of material on the same production line. The timely and carbon-emissions-efficient material distribution in the mixed flow production line are key issues to be considered in the future.

Author Contributions: X.Z. proposed the initial idea and carried out the modelling, calculations, and experiments, and wrote the manuscript. L.W., and Y.C. contributed to fine-tune the analysis and discussion.

Funding: This work is funded by the National Natural Science Foundation of China (grant no. 61702352).

Conflicts of Interest: The authors declare no conflict of interest.

\section{References}

1. Wang, X. Changes in CO2 Emissions Induced by Agricultural Inputs in China over 1991-2014. Sustainability 2016, 8, 414. [CrossRef]

2. Zhang, X.P.; Cheng, X.M. Energy consumption, carbon emissions, and economic growth in China. Ecol. Econ. 2009, 68, 2706-2712. [CrossRef]

3. Shaw, K.; Shankar, R.; Yadav, S.S.; Thakur, L.S. Modeling a low-carbon garment supply chain. Prod. Plan. Control. 2013, 24, 851-865. [CrossRef]

4. Munasinghe, M.; Jayasinghe, P.; Ralapanawe, V.; Gajanayake, A. Supply/value chain analysis of carbon and energy footprint of garment manufacturing in Sri Lanka. Sustain. Prod. Consum. 2016, 5, 51-64. [CrossRef]

5. Govindan, K.; Jafarian, A.; Khodaverdi, R.; Devika, K. Two-echelon multiple-vehicle location-routing problem with time windows for optimization of sustainable supply chain network of perishable food. Int. J. Prod. Econ. 2014, 152, 9-28. [CrossRef]

6. Monostori, L.; Valckenaers, P.; Dolgui, A.; Panetto, H.; Brdys, M.; Csáji, B.C. Cooperative control in production and logistics. Annu. Rev. Control. 2015, 39, 12-29. [CrossRef]

7. Zhou, B.H.; Shen, C.Y. Multi-objective optimization of material delivery for mixed model assembly lines with energy consideration. J. Clean. Prod. 2018, 192, 293-305. [CrossRef]

8. Nielsen, I.; Do, N.A.D.; Banaszak, Z.A.; Janardhanan, M.N. Material supply scheduling in a ubiquitous manufacturing system. Robot. Comput. Integr. Manuf. 2017, 45, 21-33. [CrossRef]

9. Kilic, H.S.; Durmusoglu, M.B. A mathematical model and a heuristic approach for periodic material delivery in lean production environment. Int. J. Adv. Manuf. Technol. 2013, 69, 977-992.

10. Wang, J.; Chang, Q.; Xiao, G.; Wang, N.; Li, S. Data driven production modeling and simulation of complex automobile general assembly plant. Comput. Ind. 2011, 62, 765-775. [CrossRef]

11. Jayakumar, A.; Krishnaraj, A.K. Productivity improvement in stitching section of a garment manufacturing company. Int. J. Innov. Res. Adv. Eng. 2017, 4, 8-11.

12. Zhou, B.; Peng, T. Scheduling the in-house logistics distribution for automotive assembly lines with just-in-time principles. Assem. Autom. 2017, 37, 51-63. [CrossRef]

13. Mehrjoo, M.; Pasek, Z.J. Risk assessment for the supply chain of fast fashion apparel industry: A system dynamics framework. Int. J. Prod. Res. 2016, 54, 28-48. [CrossRef]

14. Nayak, R.; Padhye, R.; Wang, L.; Chatterjee, K.; Gupta, S. The role of mass customization in the apparel industry. Int. J. Fash. Des. Technol. Educ. 2015, 8, 162-172. [CrossRef]

15. Kayar, M.; Akalin, M. Comparing Heuristic and simulation methods applied to the apparel assembly line balancing problem. Fibres Text. East. Eur. 2016, 2, 131-137. [CrossRef]

16. Horoba, C. Exploring the runtime of an evolutionary algorithm for the multi-objective shortest path problem. Evol. Comput. 2010, 18, 357-381. [CrossRef] [PubMed]

17. Rahimi, M.; Baboli, A.; Rekik, Y. Multi-objective inventory routing problem: A stochastic model to consider profit, service level and green criteria. Transp. Res. Part E Logist. Transp. Rev. 2017, 101, 59-83. [CrossRef]

18. Ghoseiri, K.; Nadjari, B. An ant colony optimization algorithm for the bi-objective shortest path problem. Appl. Soft Comput. 2010, 10, 1237-1246. [CrossRef] 
19. Mohamed, C.; Bassem, J.; Taicir, L. A genetic algorithms to solve the bicriteria shortest path problem. Electron. Notes Discret. Math. 2010, 36, 851-858. [CrossRef]

20. Deb, K.; Agrawal, S.; Pratap, A.; Meyarivan, T. A fast elitist non-dominated sorting genetic algorithm for multi-objective optimization: NSGA-II. In Proceedings of the IEEE Transactions on Evolutionary Computation, Berlin, Germany, 7 August 2002.

21. Murugan, P.; Kannan, S.; Baskar, S. NSGA-II algorithm for multi-objective generation expansion planning problem. Electr. Power Syst. Res. 2009, 79, 622-628. [CrossRef]

22. Jozefowiez, N.; Semet, F.; Talbi, E.G. Enhancements of NSGA II and Its Application to the Vehicle Routing Problem with Route Balancing. In Proceedings of the International Conference on Artificial Evolution (Evolution Artificielle), Lille, France, 26-28 October 2005.

23. Huayu, X.; Wenhui, F.; Tian, W.; Lijun, Y. An Or-opt NSGA-II algorithm for multi-objective vehicle routing problem with time windows. In Proceedings of the IEEE Conference on Automation Science and Engineering, Arlington, VA, USA, 23-26 August 2008.

24. Jemai, J.; Zekri, M.; Mellouli, K. An NSGA-II Algorithm for the Green Vehicle Routing Problem. In Proceedings of the European Conference on Evolutionary Computation in Combinatorial Optimization, Málaga, Spain, 11-13 April 2012.

25. Chand, P.; Mohanty, J.R. Multi objective genetic approach for solving vehicle routing problem. Int. J. Comput. Theory Eng. 2013, 5, 846-849. [CrossRef]

26. Hansen, P.; Mladenovic, N. Variable neighborhood search: Principles and applications. Eur. J. Oper. Res. 2001, 130, 449-467. [CrossRef]

27. Wu, W.; Simpson, A.R.; Maier, H.R. Accounting for greenhouse gas emissions in multi objective genetic algorithm optimization of water distribution systems. J. Water Resour. Plan. Manag. 2009, 136, 146-155. [CrossRef]

28. Soysal, M.; Bloemhof-Ruwaard, J.M.; Van der Vorst, J.G.A. Modelling food logistics networks with emissions considerations: The case of an international beef supply chain. Int. J. Prod. Econ. 2014, 152, 57-70. [CrossRef]

29. Bauer, J.; Bektaş, T.; Crainic, T.G. Minimizing greenhouse gas emissions in intermodal freight transport: An application to rail service design. J. Oper. Res. Soc. 2010, 61, 530-542. [CrossRef]

30. Elbouzekri, A.; Elhassania, M.; Alaoui, A.E.H. A hybrid ant colony system for green capacitated vehicle routing problem in sustainable transport. J. Theor. Appl. Inf. Technol. 2013, 54, 198-208.

31. Erdoğan, S.; Miller-Hooks, E. A green vehicle routing problem. Transp. Res. Part E Logist. Transp. Rev. 2012, 48, 100-114. [CrossRef]

32. Montané, F.A.T.; Galvão, R.D. Vehicle routing problems with simultaneous pick-up and delivery service. Opsearch 2002, 39, 19-33. [CrossRef]

33. Figliozzi, M. Vehicle routing problem for emissions minimization. Transp. Res. Rec. J. Transp. Res. Board. 2010, 2197, 1-7. [CrossRef]

34. Kuo, T.C.; Chen, G.Y.H.; Wang, M.L.; Ho, M.W. Carbon footprint inventory route planning and selection of hot spot suppliers. Int. J. Prod. Econ. 2014, 150, 125-139. [CrossRef]

35. Konur, D. Carbon constrained integrated inventory control and truckload transportation with heterogeneous freight trucks. Int. J. Prod. Econ. 2014, 153, 268-279. [CrossRef]

36. Wang, S.; Tao, F.; Shi, Y.; Wen, H. Optimization of vehicle routing problem with time windows for cold chain logistics based on carbon tax. Sustainability 2017, 9, 694. [CrossRef]

37. Sedighizadeh, D.; Mazaheripour, H. Optimization of multi objective vehicle routing problem using a new hybrid algorithm based on particle swarm optimization and artificial bee colony algorithm considering Precedence constraints. Alex. Eng. J. 2018, 5, 2225-2239. [CrossRef]

38. Karakatič, S.; Podgorelec, V. A survey of genetic algorithms for solving multi depot vehicle routing problem. Appl. Soft Comput. 2015, 27, 519-532. [CrossRef]

39. Wang, C.; Guan, Z.; Shao, X.; Ullah, S. Simulation-based optimization of logistics distribution system for an assembly line with path constraints. Int. J. Prod. Res. 2014, 52, 3538-3551. [CrossRef]

40. Song, L.; Jin, S.; Tang, P. Simulation and optimization of logistics distribution for an engine production line. J. Ind. Eng. Manag. 2016, 9, 59-72. [CrossRef]

41. Jabir, E.; Panicker, V.V.; Sridharan, R. Multi-objective optimization model for a green vehicle routing problem. Procedia Soc. Behav. Sci. 2015, 189, 33-39. [CrossRef] 
42. Lin, J.; FU, P.; Li, X.; Zhang, J.; Zhu, D. Study on Vehicle Routing Problem and Tabu Search Algorithm under Low-carbon Environment. Chin. J. Manag. Sci. 2015, 23, 98-106.

43. Xiangguo, M.; Tongjuan, L.; Pingzhe, Y.; Rongfen, J. Vehicle Routing Optimization Model of Cold Chain Logistics Based on Stochastic Demand. J. Syst. Simul. 2016, 8, 1824-1832.

44. Liu, W.Y.; Lin, C.C.; Chiu, C.R.; Tsao, Y.S.; Wang, Q. Minimizing the Carbon Footprint for the Time-Dependent Heterogeneous-Fleet Vehicle Routing Problem with Alternative Paths. Sustainability 2014, 6, 4658-4684. [CrossRef]

45. Rabbani, M.; Farrokhi-Asl, H.; Asgarian, B. Solving a bi-objective location routing problem by a NSGA-II combined with clustering approach: Application in waste collection problem. J. Ind. Eng. Int. 2017, 13, 13-27. [CrossRef]

46. Mendes, R.S.; Wanner, E.F.; Martins, F.V.C. Optimization of the vehicle routing problem with demand responsive transport using the NSGA-II algorithm. In Proceedings of the 19th International Conference on Intelligent Transportation Systems, Rio De Janeiro, Brazil, 1-4 November 2016.

47. Psychas, I.D.; Marinaki, M.; Marinakis, Y. A parallel multi-start NSGA II algorithm for multi objective energy reduction vehicle routing problem. In Proceedings of the International Conference on Evolutionary Multi-Criterion Optimization, Guimarães, Portugal, 29 March-1 April 2015.

48. Liu, P.; Wang, B.B.; Zhao, X.G.; Duan, X.L.; Huang, N.; Chen, Y.D.; Wang, L.M. Study on Adult Respiratory Rate in China. J. Environ. Health. 2014, 31, 953-956.

49. Radford Jr, E.P. Ventilation standards for use in artificial respiration. J. Appl. Physiol. 1955, 7, 451-460. [CrossRef] [PubMed]

50. Hu, S.J. Evolving paradigms of manufacturing: From mass production to mass customization and personalization. Procedia CIRP 2013, 7, 3-8. [CrossRef]

51. Tu, Q.; Vonderembse, M.A.; Ragu-Nathan, T.S.; Ragu-Nathan, B. Measuring modularity-based manufacturing practices and their impact on mass customization capability: A customer-driven perspective. Decis. Sci. 2004, 35, 147-168. [CrossRef]

52. Kumar, A. From mass customization to mass personalization: A strategic transformation. Int. J. Flex. Manuf. Syst. 2007, 19, 533. [CrossRef]

(C) 2019 by the authors. Licensee MDPI, Basel, Switzerland. This article is an open access article distributed under the terms and conditions of the Creative Commons Attribution (CC BY) license (http://creativecommons.org/licenses/by/4.0/). 